\title{
A Case of Protein-Losing Enteropathy Treated with Methotrexate in a Dog
}

\author{
Masashi YUKI ${ }^{1}$, Noriko SUGIMOTO ${ }^{1}$, Kuniaki TAKAHASHI ${ }^{1}$, Hiromi OTSUKA ${ }^{1)}$, Naohito NISHII ${ }^{1)}$, \\ Kiyomi SUZUKI ${ }^{1)}$, Tetsushi YAMAGAMI ${ }^{2}$ and Hiroshi ITO $^{3)}$ \\ 1) Yuki Animal Hospital, 2-99 Kibacho, Minatoku, Nagoya, Aichi 455-0021, 2) MARUPI LIFETECH Co., Ltd., 103 Fushinocho, Ikedashi, \\ Osaka 563-8691 and ${ }^{3)}$ Second Department of Veterinary Small Animal Surgery, School of Medicine and Animal Sciences, Kitasato \\ University, 23-35-1 Higashi, Towada, Aomori 034-8628, Japan
}

(Received 27 June 2005/Accepted 20 December 2005)

ABSTRACT. A 9-year-old female Pug was presented to us with chronic diarrhea. Hematologic findings indicated severe hypoproteinemia and hypoalbuminemia, and endoscopy revealed severe edema of the duodenal mucosa. Based on these results and on additional histopathological findings, we made a diagnosis of protein-losing enteropathy caused by lymphocytic-plasmacytic enteritis with lymphangiectasia. The dog was initially treated with prednisolone and cyclosporine. This treatment regimen was not effective. However, when methotrexate was substituted for cyclosporine, progress was obtained and the diagnosis was confirmed. KEY WORDS: canine, methotrexate, protein-losing enteropathy.

Hypoalbuminemia resulting from protein-losing enteropathy (PLE) can be diagnosed after elimination of liver disease and protein-losing nephropathy as potential causes of the low protein state [12]. Although PLE may occur secondary to such conditions as chronic inflammation in small intestinal diseases, it is often caused by intestinal lymphangiectasia following lymphocytic-plasmacytic enteritis [13, 16]. Immunosuppressive drugs, such as prednisolone and azathioprine, are often used in the treatment of this disorder $[16,18]$, but achievement and maintenance of remission may be difficult using these agents alone [19]. In the present case, despite using a combination of prednisolone and cyclosporine, which is a potent, rapid-acting, immunosuppressive agent [19], the expected effect was not obtained. However, improvement was confirmed when methotrexate (MTX) was substituted for cyclosporine, and rapid remission was achieved and maintained. The following is a summary of the therapeutic approach that was used.

A 9-year-old female Pug was referred to our hospital with a one-month history of diarrhea. Physical examination was unremarkable. Laboratory data at the time of admission revealed moderate leukocytosis $(32,300 / \mu l)$, severe hypoproteinemia $(3.8 \mathrm{~g} / \mathrm{d} l)$, severe hypoalbuminemia $(1.0 \mathrm{mg} /$ $\mathrm{d} l$ ), mild elevation of aspartate aminotransferase (73 U/l) and alkaline phosphatase $(222 \mathrm{U} / \mathrm{l})$, and increased C-reactive protein $(6.9 \mathrm{mg} / \mathrm{d} l)$ (Table 1). Fecal examination for internal parasites was negative. Urinalysis was normal. Although an abnormal colonic gas pattern was observed on abdominal radiography, abdominal ultrasound was unremarkable.

The following day, endoscopic examination was performed. Mild patchy erosive mucosal changes were noted in the gastric mucosa. The duodenal mucosa exhibited severe edema, increased granularity, and patchy erosive mucosal changes, and appeared friable upon biopsy. Ulcer formation was noted in part of the duodenal mucosa (Fig. 1). Histopathological review of biopsy specimens confirmed normal gastric mucosal and duodenal mucosal inflammation consistent with severe plasmacytic infiltration, mild lymphocytic infiltration, and neutrophilic infiltration. The lymphatics of these areas were slightly dilated (Fig. 2).

A diagnosis of PLE secondary to lymphocytic-plasmacytic enteritis was made at the point. Treatment with ampicillin (20 mg/kg, SC, bid), prednisolone (1 mg/kg, SC, bid), and metronidazole $(12.5 \mathrm{mg} / \mathrm{kg}, \mathrm{PO}$, bid) was initiated on the second day after admission. However, since the total

Table 1. Laboratory findings in a dog with protein-losing enteropathy (PLE)

\begin{tabular}{llrllrlll}
\hline WBC & $(/ \mu l)$ & 32300 & ALT & $(\mathrm{U} / l)$ & 44 & TBA (ante cibum) & $(\mu \mathrm{mol} / l)$ & 5.4 \\
Band & $(/ \mu l)$ & 1292 & AST & $(\mathrm{U} / l)$ & 73 & TBA (post cibum $2 \mathrm{hr})$ & $(\mu \mathrm{mol} / l)$ & 5.3 \\
Seg & $(/ \mu l)$ & 21964 & ALP & $(\mathrm{U} / l)$ & 222 & CRP & \\
Lym & $(/ \mu l$ & 4845 & T.Bil. & $(\mathrm{mg} / \mathrm{d} l)$ & 0.3 & & & \\
Mono & $(/ \mu l)$ & 4199 & LDH & $(\mathrm{U} / l)$ & 109 & & \\
Eos & $(/ \mu l$ & 0 & Tcho & $(\mathrm{mg} / \mathrm{d} l)$ & 114 & & \\
RBC & $\left(\times 10^{6} / \mu l\right)$ & 6.61 & Alb & $(\mathrm{g} / \mathrm{d} l)$ & 1 & & \\
HGB & $(\mathrm{g} / \mathrm{d} l)$ & 16.4 & TP & $(\mathrm{g} / \mathrm{d} l)$ & 3.8 & & \\
PCV & $(\%)$ & 47 & BUN & $(\mathrm{mg} / \mathrm{d} l)$ & 9.9 & & \\
MCV & $(\mathrm{f} l)$ & 71.1 & Cre & $(\mathrm{mg} / \mathrm{d} l)$ & 0.7 & & \\
MCH & $(p \mathrm{~g})$ & 24.8 & Ca & $(\mathrm{mg} / \mathrm{d} l)$ & 8.1 & & \\
MCHC $(\mathrm{g} / \mathrm{d} l)$ & 34.9 & Glu & $(\mathrm{mg} / \mathrm{d} l)$ & 96 & & \\
PLT $\quad\left(\times 10^{4} / \mu l\right)$ & 62.1 & Amy & $(\mathrm{U} / l)$ & 1187 & & \\
\hline
\end{tabular}




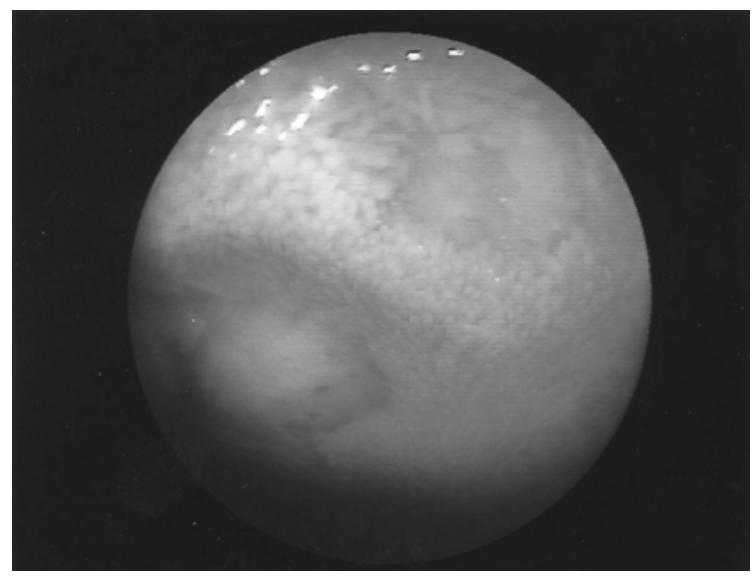

Fig. 1. Endscopic findings. The duodenal mucosal exhibited severe edema, and ulcer formation was noted in part of it.

protein level and albumin level continued to remain low on the fourth day, treatment with cyclosporine $(5 \mathrm{mg} / \mathrm{kg}, \mathrm{PO}$, bid) was initiated. On the sixth day, the cobalamin level was noted to be low at $97 \mathrm{pg} / \mathrm{ml}$, and cobalamin supplementation (50 $\mu \mathrm{g} / \mathrm{kg}, \mathrm{SC}$, once a week) was initiated. On the eighth day, since the total protein level and albumin level had decreased further, MTX $(0.6 \mathrm{mg} / \mathrm{kg}$, IM) was substituted for cyclosporine. Improvement in the total protein level and albumin level was confirmed the following day. MTX was administered five times at 7-day intervals (14th, 22nd, 29th,

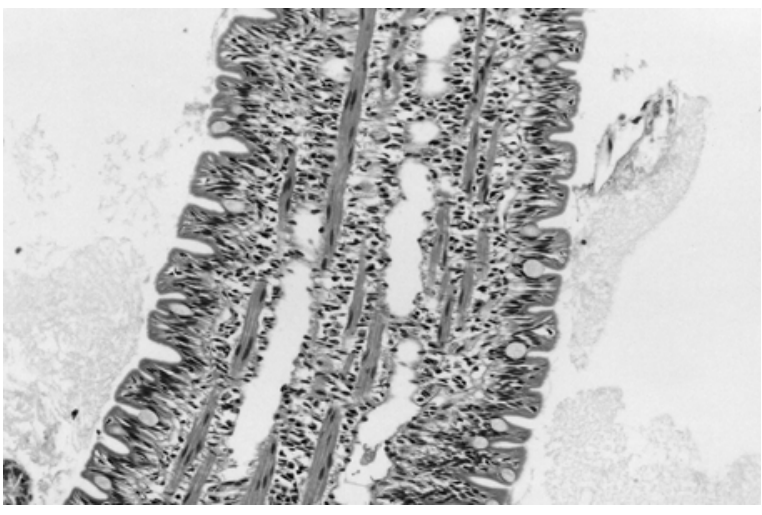

Fig. 2. Histological findings. Dilation of lymph vessels is consistent with severe plasmacytic infiltration, mild lymphocytic infiltration, and neutrophilic infiltration. H.E. $\times 100$.

and 37 th days of treatment) until complete remission was obtained. The cobalamin level then returned to a normal level $(221 \mathrm{pg} / \mathrm{m} l)$. Prednisolone dosing was gradually decreased, and complete remission was maintained with low-dose prednisolone $(0.3 \mathrm{mg} / \mathrm{kg}, \mathrm{PO}$, qod) and azathioprine $(2 \mathrm{mg} / \mathrm{kg}, \mathrm{PO}$, qod) after the 59 th day.

Since the cause of PLE is related for lymphocytic-plasmacytic enteritis in many cases, treatment for lymphocyticplasmacytic enteritis is often effective in alleviating PLE $[16,18]$. A recent report documented increased $\operatorname{IgA}{ }^{+}$and $\mathrm{IgG}^{+}$plasma cells and $\mathrm{T}$ cells in dogs with lymphocytic-

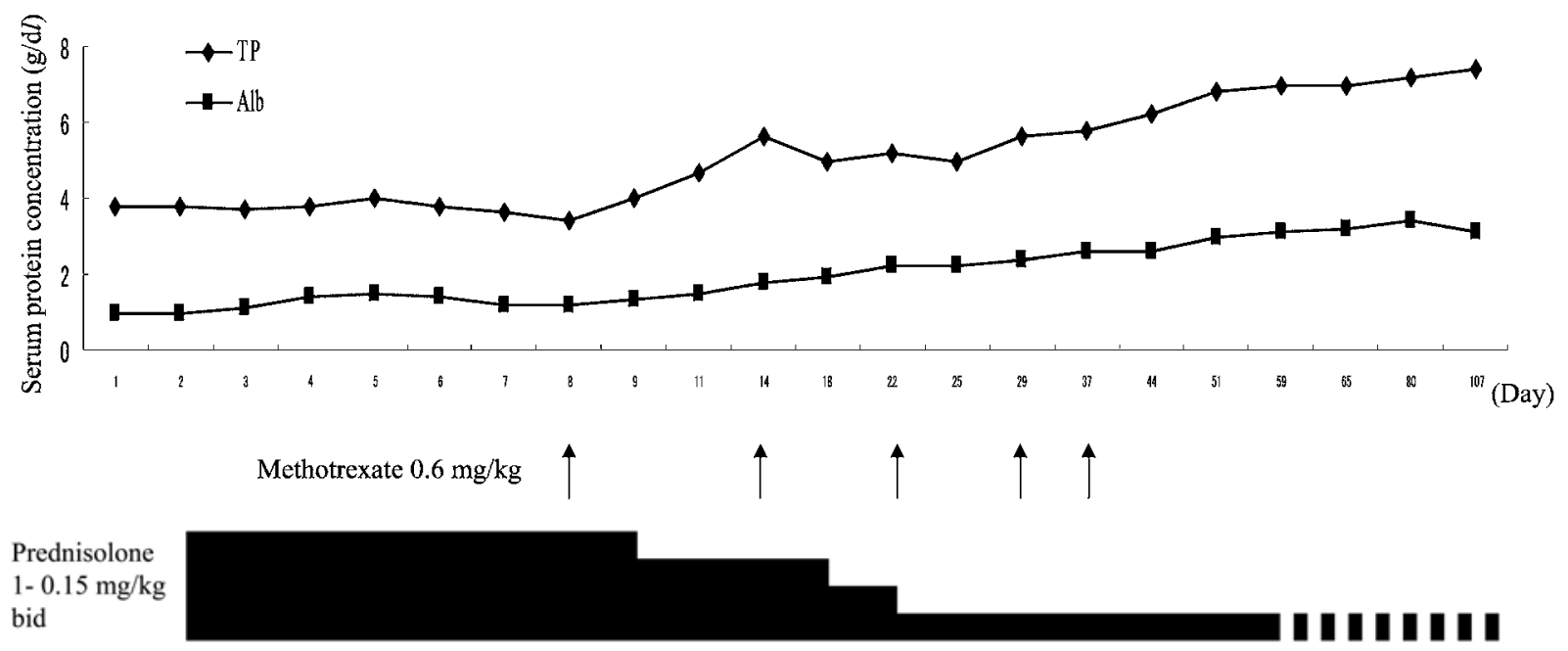

Cyclosporine $5 \mathrm{mg} / \mathrm{kg}$ bid

Azathioprine $2 \mathrm{mg} / \mathrm{kg}$ sid

Metronidazole

$12.5 \mathrm{mg} / \mathrm{kg}$ bid

Fig. 3. Methotrexate regimen for treatment of steroid refractory protein-losing enteropathy (PLE). 
plasmacytic colitis [10]. Other reports have documented increased interleukin (IL)-2, IL-5, IL-12p40, interferon- $\gamma$, tumor necrosis factor- $\alpha$, and transforming growth factor- $\beta$ in canine small intestine inflammatory bowel disease (IBD) [8]. Therefore, immunosuppressive treatment with prednisolone is generally selected. In severe cases or for patients who respond poorly to prednisolone alone, azathioprine may be added [16]. However, azathioprine has a lag effect, with beneficial therapeutic results often not apparent until 3 to 4 weeks after treatment is initiated [18].

In recent reviews of human refractory IBD, the calcineurin inhibitors cyclosporine and tacrolimus had therapeutic efficacy, while azathioprine did not $[4,9]$. Moreover, a report of a canine case documented improvement within one week after oral administration of cyclosporine [19]. In the present case, however, the expected effect was not obtained despite the fact that the blood concentration of cyclosporine reached the recommended concentration of $350 \mathrm{ng} / \mathrm{m} l$ [15].

MTX is an antimetabolite (a folic acid inhibitor) with both immunosuppressant and anti-inflammatory activity. The drug also has molecular homology to IL-1 and interferes with the inflammatory action of IL-2 [3]. In human rheumatoid arthritis, the anti-inflammatory effect of MTX in joints occurs in the absence of any decrease in inflammatory cell infiltration, and evidence of an anti-inflammatory effect is detected within $24 \mathrm{hr}$ of administration, which is too soon to be explained by inhibition of cellular proliferation [2]. Furthermore, MTX has been shown to be effective at low doses ( $25 \mathrm{mg}$ or less once a week, intramuscularly) in several human cases of chronic IBD $[5,6]$. Low-dose MTX therapy inhibits production of thymidylate, purines, and methionine, and leads to accumulation of adenosine, a potent anti-inflammatory substance. These actions inhibit cellular proliferation, decrease formation of antibodies, and decrease production of various inflammatory mediators, including interleukins and eicosanoids [5]. On the basis of this data, MTX was used in the present case because of its immunosuppressive and antinflammatory effects in the context of lymphocytic-plasmacytic enteritis. Until now, use of MTX in the dog has been restricted to treatment of neoplasia $[1,11,14]$, and the dosage of MTX used in recent combination chemotherapy protocols for lymphoma has been $0.6-$ $0.8 \mathrm{mg} / \mathrm{kg}[11,14]$. This was the basis for selecting a dose of $0.6 \mathrm{mg} / \mathrm{kg}$, as no dosages have been reported for canine immunosuppressive treatment. From the day after medication, total protein and albumin levels began to increase, and these parameters normalized within one week. Diarrhea also improved simultaneously. MTX was then administered intramuscularly for a total of 5 times at weekly intervals up to the 37 th day, at which point the azathioprine was expected to become effective. Even after completion of the MTX treatment, subsequent progress has remained good with azathioprine and low dose prednisolone.

The most common side effect of MTX is gastrointestinal toxicity resulting in diarrhea, vomiting and anorexia, hepa- totoxicity, and bone marrow suppression [17]. However, these side effects did not appear in the present case. A report of IBD in a dog has suggested a tendency toward cobalamin deficiency [7]. In the present case, the serum cobalamin concentration before MTX administration was low at $97 \mathrm{pg} / \mathrm{ml}$ (lower limit of normal range $=215 \mathrm{pg} / \mathrm{m} l$ [7]). However, cobalamin levels improved in response to 6 weeks of MTX with cobalamin supplementation. Consequently, when using MTX for IBD, we advocate monitoring of the serum cobalamin concentration.

In conclusion, the use of MTX in small animals has been restricted to the treatment of neoplasia. However, it is possible that MTX could become the treatment of choice for PLE, which requires anti-inflammatory and immunosuppressive treatment.

\section{REFERENCES}

1. Amber, E. I., Henderson, R. A., Adeyanju, J. B. and Gyang, E. O. 1990. J. Vet.Intern. Med. 4: 144-147.

2. Cronstein, B. N. 1992. Inflammation. 16: 411-423.

3. Debinski, H. S. and Kamm, M. A. 1995. Eur. J. Gastroenterol. Hepatol. 7: 169-182.

4. de, Oca. J., Vilar, L., Castellote, J., Sanchez, Santos. R., Pares, D., Biondo, S., Osorio, A., del, Rio. C., Jaurrieta, E. and Marti, R. J. 2003. Rev. Esp. Enferm. Dig. 95: 465-470.

5. Egan, L. J. and Sandborn, W. J. 1996. Mayo. Clin. Proc. 71: 69-80.

6. Feagan, B. G., Fedorak, R. N., Irvine, E. J., Wild, G., Sutherland, L., Steinhart, A. H., Greenberg, G. R., Koval, J., Wong, C. J., Hopkins, M., Hanauer, S. B. and McDonald, J. W. 2000. New Engl. J. Med. 342: 1627-1632.

7. German, A. J., Day, M. J., Ruaux, C. G., Steiner, J. M., Williams, D. A. and Hall, E. J. 2003. J. Vet. Intern. Med. 17: 33-43.

8. German, A. J., Helps, C. R., Hall, E. J. and Day, M. J. 2000. Dig. Dis. Sci. 45: 7-17.

9. Hisamatsu, T. and Hibi, T. 1998. J. Gastroenterol. 33: 609611.

10. Jergens, A. E., Gamet, Y., Moore, F. M., Niyo, Y., Tsao, C. and Smith, B. 1999. Am. J. Vet. Res. 60: 515-520.

11. Keller, E. T., MacEwen, E. G., Rosenthal, R. C., Helfand, S. C. and Fox, L. E. 1993. J. Vet. Intern. Med. 7: 289-295.

12. Kimmel, S. E., Waddell, L. S. and Michel, K. E. 2000. J. Am. Vet. Med. Assoc. 217: 703-706.

13. Kull, P. A., Hess, R. S., Craig, L. E., Saunders, H. M. and Washabau, R. J. 2001. J. Am. Vet. Med. Assoc. 219: 197-202.

14. MacEwen, E. G., Hayes, A. A., Matus, R. E. and Kurzman, I. 1987. J. Am. Vet. Med. Assoc. 190: 564-568.

15. Mathews, K. A. and Sukhiani, H. R. 1997. J. Am. Vet. Med. Assoc. 15: 1249-1253.

16. Melzer, K. J. and Sellon, R. K. 2002. Compend. Contin. Educ. Pract. Vet. 24: 953-961.

17. Miller, E. 1997. Semin. Vet. Med. Surg (Small Anim). 12: 157160.

18. Tams, T. R. 2003. pp. 211-250. In: Handbook of Small Animal Gastroenterology, 2nd ed. (Tams, T. R. ed.), Elsevier Science, Philadelphia.

19. Yuki, M., Takahashi, K., Sugimoto, N., Otsuka, H. and Suzuki, K. 2005. J. Jpn. Vet. Med. Assoc. 57: 101-104 (in Japanese). 